\title{
Análise da ventilação natural em uma habitação de interesse social, com diferentes configurações de muro, através de simulações CFD
}

\author{
Ana Clara de Almeida Xavier, \\ Marieli Azoia Lukiantchuki*
}

\begin{abstract}
Resumo A ventilação natural é uma estratégia eficiente para o condicionamento térmico passivo das edificações que, muitas vezes, é subutilizada em habitações de interesse social. Essas habitações são caracterizadas por projetos padrões, que desconsideram o clima da região, e pela presença de muros que impactam significativamente o aproveitamento dos ventos. O artigo avalia a ventilação natural nos espaços internos com três configurações de muro: a habitação sem muro, com muro impermeável e uma configuração permeável, através de simulações CFD. Nota-se que o muro permeável apresenta desempenho semelhante ao caso sem muro, possibilitando que o fluxo de ar atinja os ambientes internos, além de manter a segurança e a privacidade dos moradores. Destaca-se, por fim, que é necessária a revisão das normativas.
\end{abstract}

Palavras-chave: ventilação natural, simulações CFD, habitações de interesse social.

\section{Análisis de la ventilación natural en una habitacion social con diferentes configuracio- nes de pared utilizando simulaciones CFD}

\begin{abstract}
Resumen La ventilación natural es una estrategia eficiente para el acondicionamiento térmico pasivo de edificios, que a menudo no se considera en viviendas de interés sociales. Estas habitaciones se caracterizan por proyectos estándar que desconocen el clima de la región y la presencia de paredes que impactan significativamente el uso de los vientos. El artículo evalúa la ventilación natural en espacios internos con tres configuraciones de pared: la vivienda sin pared, con un pared impermeable y una configuración permeable, mediante simulaciones CFD. Se observa que la pared permeable presenta un desempeño similar al habitacion sin pared, permitiendo que el flujo de aire llegue a los ambientes interiores, mientras de mantene la seguridad y privacidad de los residentes. Finalmente, se destaca que es necesario revisar la normativa.
\end{abstract}

Palabras clave: ventilación natural, simulaciones de CFD, vivienda de interés social.

\section{Natural ventilation analysis in a Social Housing Program with different wall configu- rations through CFD simulations}

\begin{abstract}
Natural ventilation is an efficient strategy for passive thermal conditioning of buildings, which is often not used in social housings. These houses are characterized by standard projects that do not consider region's climate and by the present of walls which significantly impacting on the use of winds. This article evaluates natural ventilation of indoor spaces with three different configurations of walls: housing with no wall, with impermeable wall and with a permeable configuration, through CFD simulations. It can be noticed that the permeable wall has a similar performance to the no wall configuration, allowing the air flow to reach indoor environments, at the same time to maintaining the user's security and privacy. Finally, it should be pointed that it is necessary to revise the regulations.
\end{abstract}

Keywords: natural ventilation, CFD simulations, social housing. 
* Ana Clara de Almeida Xavier é Estudante de Arquitetura e Urbanismo da Universidade Estadual de Maringá, ORCID <https://orcid.org/0000-0002-7186-1268>. Marieli Azoia Lukiantchuki é Arquiteta e Urbanista, Professora Adjunta na Universidade Estadual de Maringá. ORCID <https://orcid.org/0000-0003-0697-9064>.

\section{Introdução}

Brasil apresenta um déficit habitacional expressivo em todo o seu território. Como modo de suprir as necessidades habitacionais das cidades, é recorrente a criação de programas habitacionais de baixa renda (NASCIMENTO; BRAGA, 2009). Dentre os diversos programas habitacionais do Brasil, o Programa Minha Casa Minha Vida é um dos mais difundidos, apresentando como característica a customização em massa que implanta edificações padrões sem levar em consideração questões ambientais. Isso acarreta uma baixa qualidade das habitações, como já foi constatado em diversas pesquisas científicas (NASCIMENTO; BRAGA, 2009; REIS; LAY, 2010; MORAES; LABAKI, 2017; CARVALHO; SPOSTO, 2012). Além disso, essas habitações, principalmente as tipologias horizontais, são implantados em lotes pequenos com a presença de muros em todo o seu perímetro. Segundo Da Costa (2018) esse elemento está presente no contexto urbano do país, visando maior segurança e privacidade dos moradores. No entanto, a presença dos muros impacta significativamente no aproveitamento da ventilação natural, configurando-se como uma problemática para o conforto térmico da habitação.

Atualmente existem normativas brasileiras que recomendam soluções projetuais para HIS baseadas em parâmetros mínimos, como a NBR 15.220 (ABNT, 2005) e a NBR 15.575 (ABNT, 2013), visando a garantia das condições de habitabilidade e conforto dos usuários. No entanto, mesmo com o auxílio desses documentos, os projetos arquitetônicos das moradias ainda se configuram com aberturas mínimas para uma efetiva ventilação natural, a implantação muitas vezes não é adequada com relação à insolação e à ventilação, a especificação dos sistemas construtivos, assim como as cores destes, não considera os aspectos térmicos, entre outros fatores, evidenciando que a problemática da moradia em relação ao conforto térmico ainda se mantém (FERREIRA et al., 2017, RABELO et al., 2012).

Segundo Lamberts et al. (2014) o Brasil, devido ao seu imenso território e por se localizar entre dois trópicos, possui um clima bastante variado, sendo que grande parte do território brasileiro é classificado como tendo um clima quente e úmido. Nestas regiões, a combinação de estratégias de ventilação natural e de sombreamento das aberturas pode contribuir significativamente para a redução do condicionamento artificial e, consequentemente, do consumo energético nas edificações. No Zoneamento Bioclimático Brasileiro, apresentado na NBR 15220-3 (ABNT, 2005), a ventilação natural é recomendada em sete das oito zonas bioclimáticas brasileiras. Dessa forma, o desenvolvimento de pesquisas que utilizem estratégias que proporcionem a ventilação natural nos ambientes internos de HIS é de grande relevância (MORAES; LABAKI, 2017, MERCADO et al., 2010, GRIGOLETTI; LINCK, 2014, LÔBO; BITTENCOURT, 2003).

Para a avaliação do desempenho da ventilação natural, existem diversos métodos que podem ser utilizados durante a concepção do projeto, tais como: 1) experimentos em túnel de vento; 2) experimentos em mesas d'água; 3) experimentos em tamanho real; 4) simulação computacional por dinâmica dos fluidos computacional - CFD e 5) fórmulas 
analíticas e semi-empíricas (CHEN, 2009). Cada um desses métodos apresenta vantagens e desvantagens indicando qual o melhor para cada caso específico. Dentre estes, a simulação CFD tem sido amplamente utilizada, ressaltando que no Brasil, diversas pesquisas relevantes têm sido efetuadas utilizando essa técnica tanto em meio urbano (COSTA, 2001; PRATASHIMOMURA, 2005; LEITE, 2010) como nas edificações (CÓSTOLA, 2006; LUKIANTCHUKI, 2015; ANDRADE, 2013), o que comprova a eficiência do método.

Diante disso, o objetivo desse artigo é analisar o desempenho da ventilação natural por ação dos ventos em uma habitação de interesse social (HIS) com três diferentes configurações de muro na cidade de Maringá - PR, a fim de contribuir para a reflexão sobre a qualidade desses projetos no país.

\section{Método}

O método desse trabalho foi dividido em quatro etapas: seleção dos casos analisados; caracterizaçã̃o climática; simulações computacionais; e parâmetros de análise dos resultados.

\subsection{Seleção dos casos analisados}

A unidade habitacional analisada nessa pesquisa é pertencente ao Programa Minha Casa Minha Vida. A escolha se deu devido a abrangência social do referido programa e por sua característica de reprodução de projetos padrões sem considerar aspectos climáticos do local de implantação da edificação, implicando em diversos problemas de conforto térmico (MORAIS et al., 2017 e MORAIS; LABAKI, 2017). Escolheu-se uma habitação térrea, devido a maior interferência da cobertura nos ganhos térmicos para os ambientes internos e pela inclusão do muro lateral posteriormente pelos habitantes.

Dentre os conjuntos habitacionais presentes na cidade de Maringá - PR, escolheu-se um modelo de habitação do conjunto habitacional Jardim Oriental, sendo o lote de geometria retangular com $10 \mathrm{~m}$ de testada e $20 \mathrm{~m}$ de profundidade, totalizando $200 \mathrm{~m}^{2}$ de área. A casa de formato também retangular apresenta dimensões de $5,46 \mathrm{~m}$ por 7,86m e está implantada de maneira centralizada com a menor medida paralela a testada do terreno. $\mathrm{O}$ lote e a casa têm $23^{\circ}$ de inclinação a oeste em relação ao norte. O programa da habitação é composto de dois dormitórios, um banheiro, sala de estar e a cozinha/jantar, possuindo uma cobertura em duas águas de inclinação 25\% (Figura 1).

Todos os cômodos apresentam apenas uma abertura para o exterior cujas dimensões padronizadas são de 1,50m de largura e 1,20m de altura, com duas folhas fixas na parte superior e quatro folhas inferior com abertura de correr, o que configura em uma área efetiva de ventilação de $37,5 \%$. A abertura do banheiro tem dimensão de $1,00 \mathrm{~m}$ de largura e $0,60 \mathrm{~m}$ de altura, do tipo basculante, configurando uma área efetiva de ventilação de $30 \%$ (Figura 2).

As habitações desse programa são entregues aos usuários sem muro de divisa lateral. Por questões de segurança e privacidade o muro é uma das primeiras coisas que os usuários inserem na divisa do lote. Diante disso, nessa pesquisa foram analisados três casos: a edificação sem muro, representando a situação em que a HIS é entregue aos moradores (CSM); a edificação com o muro impermeável, distante da edificação em 0,60m e com 2,50m de altura, situação atual das edificações (CMI) e o caso 3 é a possibilidade desse muro ser permeável, em uma configuração de lâminas horizontais (CMP) (figura 3). 
Figura 1 (topo): Implantação, planta e corte transversal, respectivamente, da edificação. Fonte: Acervo da Prefeitura Municipal de Maringá (2012); adaptado pelas autoras (2019).

Figura 2 (à direita): Tipologia das aberturas da edificação. Fonte: Elaborado pelas autoras (2019).

Figura 3 (embaixo): Casos analisados: (1) CSM; (2) CMI e (3) CMP, respectivamente. Fonte: Elaborado pelas autoras (2019).
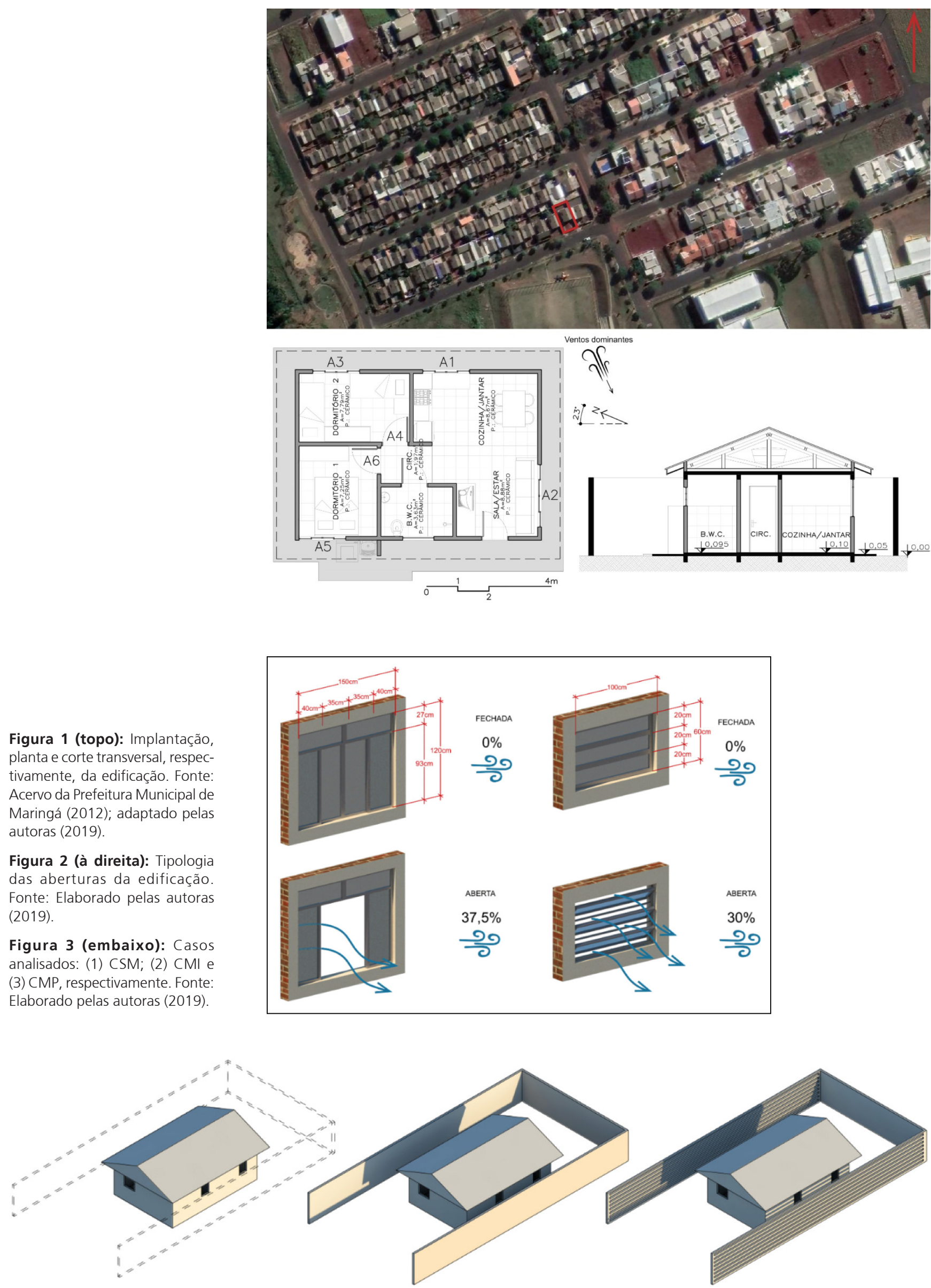
1 EPW (EnergyPlus Weather File).

Tabela 1: Coeficientes de acordo com as características do terreno. Fonte: BRE ${ }^{2}$ (1978 apud BITTENCOURT e CÂNDIDO, 2006).

2 BUILDING RESEARCH ESTABLISHMENT. Principles of natural ventilation. BRE Digest n. 210. Garston, 1978.

\subsection{Caracterização climática}

Maringá está localizada no norte do Paraná, na latitude -232 $25^{\prime} 31^{\prime \prime}$, longitude $-51^{\circ} 56^{\prime} 19^{\prime \prime}$ e altitude de 596m. Segundo a classificação de Koppen (1948) a cidade possui clima tipo Cfa, subtropical úmido de altitude, com verões quentes, concentração das chuvas nos meses de verão, sem estação de seca definida e um alto nível de radiação solar durante o ano todo. De acordo com os dados do INMET (2018) e os arquivos no formato Epw ${ }^{1}$ elaborados por Roriz (2012), as temperaturas médias variam de $18^{\circ} \mathrm{C}$ a $28,4^{\circ} \mathrm{C}$ e a umidade relativa apresenta valores em torno de $68,4 \%$. Em uma análise bioclimática (ProjetEEE, 2018), o clima de Maringá proporciona $41 \%$ das horas do ano de conforto térmico, sendo que do restante $29 \%$ do ano está em desconforto por frio e $30 \%$ do ano em desconforto por calor, demonstrando um clima em equilíbrio entre verão e inverno. Diante disso, as estratégias projetuais recomendadas são: inércia térmica para aquecimento no inverno e ventilação natural e sombreamento das aberturas no verão.

Com relação aos ventos externos, têm-se a direção predominante entre leste e nordeste com velocidades entre 0 e $4 \mathrm{~m} / \mathrm{s}$, com maior predominância de $2 \mathrm{~m} / \mathrm{s}$ (INMET, 2018). Esse valor definido é referente aos dados medidos nas estações climatológicas, a $10 \mathrm{~m}$ de altura. Com base nos valores de referência para a velocidade dos ventos externos e nas condições do entorno do edifício, existem diferentes equações que fornecem as velocidades na altura da edificação. Segundo Marques da Silva (2010), o perfil das velocidades médias de uma Camada Limite Atmosférica (CLA) pode ser descrito, de forma aproximada e simples, por uma lei do tipo potencial, dependendo do expoente ( $\alpha$ ), que é relacionado à rugosidade do terreno (equação 1). Para as simulações computacionais adotou-se como entorno um ambiente suburbano, compatível com a realidade local, com valor de a igual a 0,25 (tabela 1).Com relação aos ângulos de incidência dos ventos externos, a edificação foi simulada na situação de implantação real, ou seja, os ventos incidindo na direção NE, conforme a figura 1 .

$$
\frac{U}{U_{r e f}}=\left(\frac{h}{h_{r e f}}\right)^{\alpha}
$$

Onde:
$U_{f} \quad$ Velocidade média do vento em certa altura $\mathrm{h}(\mathrm{m} / \mathrm{s})$
$U_{\text {ref }} \quad$ Velocidade do vento medida na altura de referência $(\mathrm{m} / \mathrm{s})$
$h_{f} \quad$ Altura da edificação que se deseja avaliar a velocidade do vento $(\mathrm{m})$
$h_{\text {reff }} \quad$ Altura de referência da velocidade do vento medida (10m em geral)
$\boldsymbol{\alpha}_{\mathrm{f}} \quad$ Expoente de lei de potência da camada limite atmosférica (tabela 1)

\begin{tabular}{|l|c|c|}
\hline Coeficientes do terreno & k & a \\
\hline Área abertura plana & 0,68 & 0,17 \\
\hline Campo com obstáculos espaçados & 0,52 & 0,20 \\
\hline Área urbana & 0,35 & 0,25 \\
\hline Centro de cidade & 0,21 & 0,33 \\
\hline
\end{tabular}




\subsection{Simulações computacionais}

Para a realização das simulações, utilizou-se o software de Dinâmica dos Fluidos Computacional (CFD) CFX 12.0, Ansys. Essa ferramenta é adequada às pesquisas de análise de fluidos interno e externo nas áreas de engenharia e arquitetura e consiste nas seguintes etapas: 1) confecção da geometria da edificação; 2) geração da malha computacional; 3) determinação das condições de contorno do domínio e da edificação e 4) simulação computacional.

\subsubsection{Confecção da geometria da edificação}

Os modelos tridimensionais do edifício e do domínio foram elaborados no software AutoCAD, exportando-os para o Icem. O domínio foi construído em um formato retangular, cujas dimensões seguiram as recomendações de Harries (2005) e Tominaga et al. (2008): distância à barlavento e das laterais de $5 \mathrm{H}(20 \mathrm{~m})$, a altura de $6 \mathrm{H}(24 \mathrm{~m})$ e à sotavento de $10 \mathrm{H}(40 \mathrm{~m})$, onde $\mathrm{H}=4 \mathrm{~m}$ que corresponde à altura da habitação (Figura 4, à esquerda). Ramponi e Blocken (2012) testaram diferentes proporções de domínio e concluíram que em um domínio muito pequeno há tendência de aumento da velocidade local. A área de obstrução do edifício no domínio foi de 1,1\%, no sentido do fluxo e 1,0\% no sentido perpendicular ao fluxo, atendendo à sugestão de Franke (2004) e Tominaga et al. (2008), que recomenda um valor abaixo de 3\%. Dessa forma, evita-se o efeito de blocagem, impedindo que as fronteiras do domínio influenciem no escoamento. Para a definição das aberturas, foi considerada a dimensão da área efetiva de ventilação, de acordo com a tipologia da janela. Para as portas, todas foram consideradas abertas, com exceção das portas do banheiro e a externa de acesso à habitação, que por questões de privacidade e segurança foram modeladas fechadas. A habitação foi modelada de maneira fidedigna, considerando todos os elementos do projeto padrão, como cobertura, laje e o muro externo (Figura 4, à esquerda).

\subsubsection{Geração da malha computacional}

A precisão dos resultados alcançados em uma simulação CFD é altamente dependente da qualidade da malha computacional e tem implicação no nível de convergência do modelo (CALAUTIT e HUGHES, 2014). Para todas as simulações, utilizou-se uma malha estruturada tetraédrica, cujos parâmetros globais adotados foram: maximum element size 16; natural size 4; e cells in gap 8. A malha foi refinada nas superfícies do edifício em um valor de 0,15 m, a fim de melhorar a visualização do fluxo de ar no espaço interno e no entorno imediato ao edifício. A combinação desses parâmetros determina a quantidade de elementos da malha e, assim, o tempo de processamento das simulações (Figura 4, à direita).

De acordo com Tominaga et al. (2008), para prever o fluxo em torno de um edifício com alta precisão, é importante reproduzir corretamente as características de separar os fluxos próximos da cobertura e das paredes, ou seja, é necessário o refinamento da malha nas áreas de interesse.

\subsubsection{Definição das condições de contorno}

A precisão de uma simulação CFD é influenciada pelo modelo de turbulência, condições iniciais e de contorno. Nesta pesquisa, a definição desses fatores foi baseada em 


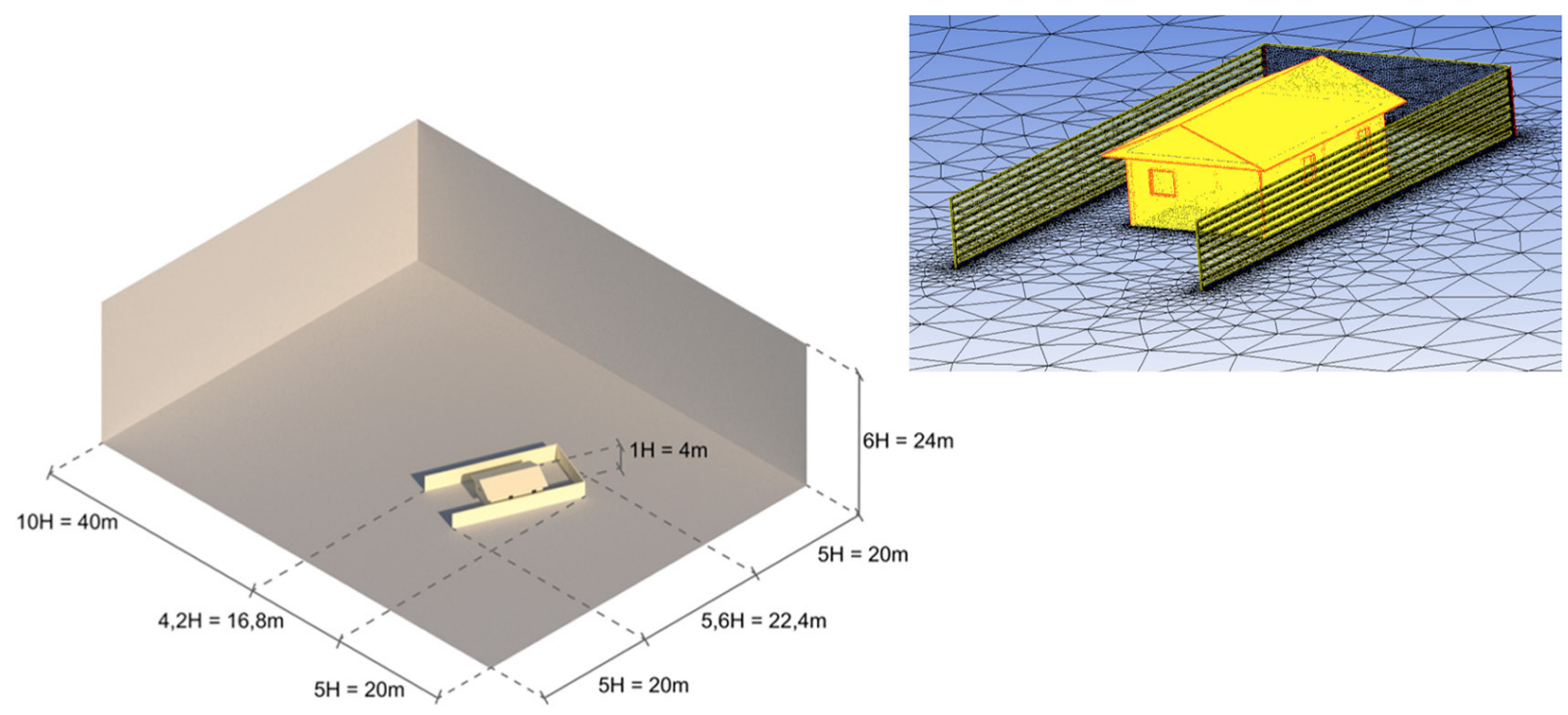

Figura 4: HIS e o domínio computacional (esquerda) e a malha computacional (direita). Fonte: Elaborado pelas autoras (2019).
Cóstola e Alucci (2007) e Tominaga et al. (2008). As condições do domínio foram definidas de modo semelhante às de um túnel de vento: entrada como INLET e saída como OUTLET. As laterais e o teto como WALL freeslip (sem atrito), pois não impõe resistência às partes do domínio onde não são realizadas análises importantes, e o piso e as superfícies do edifício como WALL no slip (com atrito).

Um perfil da camada limite atmosférica foi aplicado como condição de entrada nas simulações, utilizando a Equação 1 (Figura 5). Os parâmetros adotados para a turbulência foram: a intensidade média (5\%), o valor padrão do software; e a high resolution advection scheme; conservative auto timescale. O modelo de turbulência utilizado foi o K-epsilon, que é comum e bem estabelecido em diversas pesquisas de dinâmica dos fluidos e ventilação natural, conforme justificado em Lukiantchuki et al. (2016).

O nível de convergência foi estabelecido quando todos os níveis residuais alcançaram um valor máximo de $10^{-4}$. Os números de iterações mínimos e máximos adotados foram de 600 e 6.000, respectivamente. Esses parâmetros foram baseados em pesquisas brasileiras sobre ventilação natural, utilizando como ferramenta o CFX (BRANDÃO, 2009; COSTA, 2009; CÓSTOLA, 2006; LEITE, 2008; PRATA-SHIMOMURA, 2005).

\subsubsection{Parâmetros de análise dos resultados}

Os resultados referem-se a análises qualitativas obtidas em imagens vetoriais do fluxo de ar e quantitativas baseadas nas velocidades médias internas do fluxo de ar em cada ambiente de maior permanência (sala e quartos). Para avaliar o desempenho qualitativo da ventilação natural em planta, foi gerado um plano horizontal com a altura de 1,10m e planos verticais (cortes 1, 2, 3 e 4), passando pelas aberturas e pelo muro de divisa (Figura 6). Nesses planos, vetores de intensidade e direção do fluxo de ar foram plotados, sendo utilizada uma escala em que cada cor representa um valor de velocidade correspondente. 

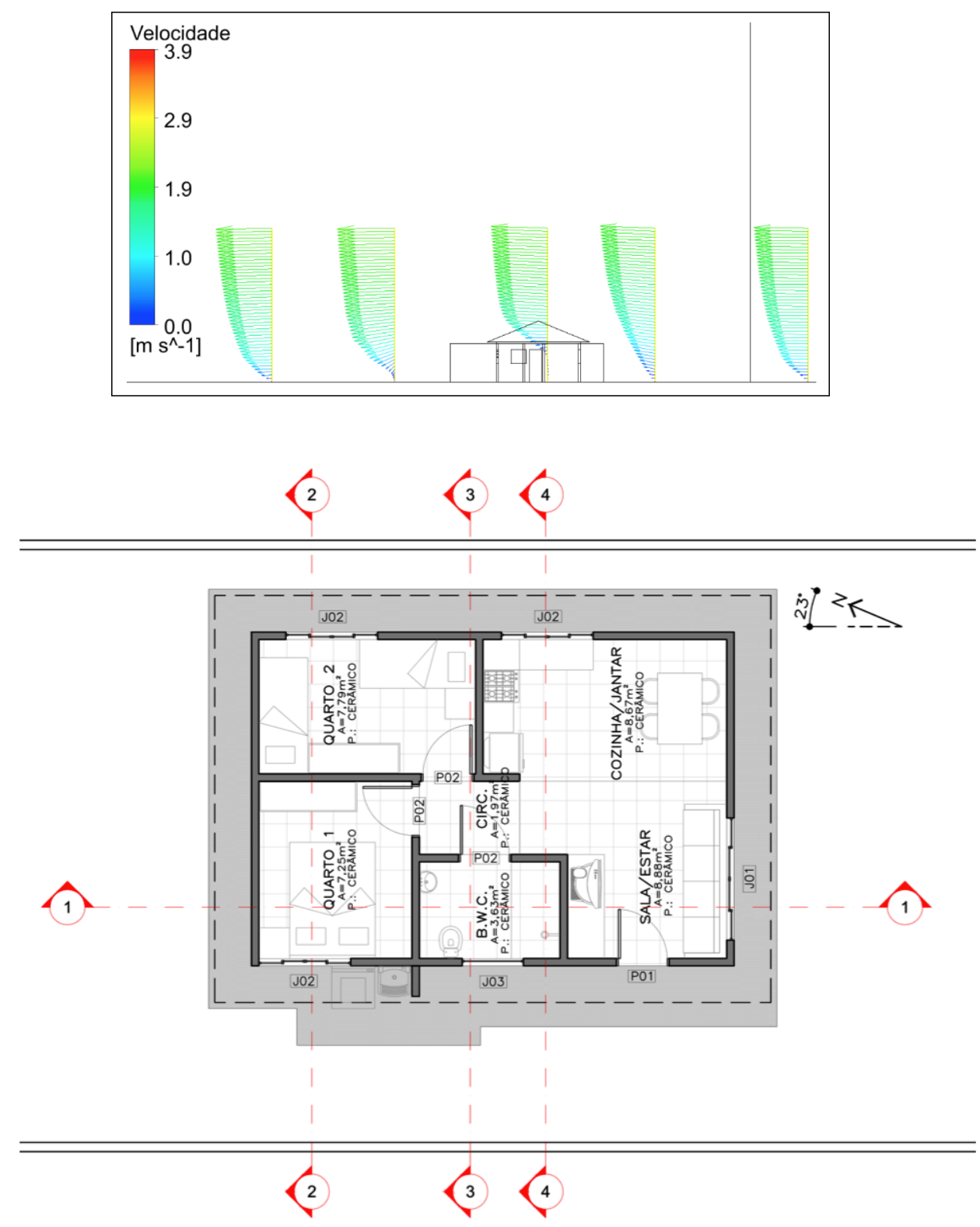

Figura 5 (topo): Perfil da Camada Limite Atmosférica gerada nas simulações computacionais. Fonte: Elaborado pelas autoras (2019).

Figura 6: Planta da HIS com os cortes estabelecidos para as análises. Fonte: Acervo da Prefeitura Municipal de Maringá (2012); adaptado pelas autoras (2019).
Posteriormente, para a análise do desempenho quantitativo, a porcentagem da área efetiva de ventilação das aberturas da HIS foi analisada com base nas recomendações da NBR 15575 (2013), a fim de verificar se estavam compatíveis com as recomendações propostas pela normativa. Em seguida, foi realizada uma análise visando o conforto dos usuários. Geralmente, os limites aceitáveis da velocidade do ar são fornecidos por normas internacionais como ASHRAE 55 (2004), ISO 7730 (2005) e EN15251 (2007). No entanto, esses e outros documentos especificam valores para a velocidade do ar inferiores aos desejados pelos usuários de países mais quentes, como o Brasil, que demandam por maior movimento do ar. Diante disso, os valores de velocidade média do ar no ambiente interno foram analisados com base nos limites propostos no trabalho de Cândido et al. (2010), onde os autores questionaram os limites de aceitabilidade do movimento do ar previsto pelas referidas normas. Experimentos práticos realizados no Brasil, pelos referidos autores (CÂNDIDO et al., 2010) demonstraram que nossos limites 
Tabela 2: Limites de aceitabilidade da velocidade do ar nos ambientes internos. Fonte: Adaptado de Cândido et al. (2010).

\begin{tabular}{|c|c|}
\hline Velocidade do ar (m/s) & Situação ocasionada \\
\hline $0-0,2$ & Ventilação natural imperceptível \\
\hline $0,2-0,4$ & Ventilação natural perceptível \\
\hline $0,4-0,8$ & $\begin{array}{l}\text { Ventilação natural satisfatória (há redução da carga térmica e contribui } \\
\qquad \text { para o conforto) }\end{array}$ \\
\hline Acima de 0,8 & $\begin{array}{l}\text { Controle necessário (causa incômodos como levantamento de papéis, } \\
\text { desordem de cabelos, roupas e objetos) }\end{array}$ \\
\hline
\end{tabular}

são diferentes dos praticados em países europeus, uma vez que em climas quentes, ou até mesmo moderadamente quentes, o mesmo movimento de ar que é considerado como desconfortável em climas frios e temperados, pode ser tido como bem-vindo pelos usuários para fins de conforto térmico. Através da pesquisa desses autores, notou-se que velocidades maiores podem ser não apenas bem aceitas como até desejadas pelos usuários. A Tabela 2 apresenta a escala elaborada com base no trabalho de Cândido et al. (2010), que amplia os limites máximos da velocidade média do ar nos espaços internos.

Em seguida calculou-se o aproveitamento interno da ventilação, conceito este proposto por Givoni (1962), definido pelo valor médio da velocidade do ar no ambiente interno dividido pelo valor do vento incidente na mesma altura (Vref está numa altura a 1,1 $\mathrm{m}$ do solo). Por fim, localizaram-se 12 pontos em cada abertura dos casos avaliados, equidistantes entre si para medição dos valores de $\mathrm{Cp}$. A medição do $\mathrm{Cp}$ foi realizada através da inserção da equação 2 para o cálculo dessa variável no CFX post. Em cada abertura, calculou-se a média do Cp.

$$
C p=\frac{\mathrm{Px}-\mathrm{Pe}}{\mathrm{Pd}}
$$

Onde:

Cp Coeficiente de pressão (adimensional)

Px Pressão em um determinado ponto da envoltória do edifício (Pa)

Pe Pressão estática de referência, do fluxo de ar não perturbado $(\mathrm{Pa})$

$\mathrm{Pd} \quad$ Pressão dinâmica do vento não perturbado $(\mathrm{Pa})$

A junção da análise quantitativa com a qualitativa é importante em pesquisas de ventilação natural. A emissão de recomendações projetuais em função da velocidade média do fluxo de ar interno não é representativa, pois, nota-se diferenças na distribuição do fluxo de ar nos diversos pontos internos e, assim, na sensação do conforto do usuário. Dessa forma, é possível determinar, por exemplo, o layout interno, em função das regiões melhor atingidas pela corrente de ar. Ressalta-se ainda que o conforto térmico do usuário pode variar conforme as estações do ano, entre uma preferência por maior ou menor exposição à corrente de ar. 
Figura 7: Velocidade média do fluxo de ar interno com a porcentagem de aproveitamento em relação aos ventos externos, para cada caso analisado. Fonte: Elaborado pelas autoras (2019).

\section{Resultados}

A seguir são apresentados os resultados obtidos para a situação em que a habitação é entregue aos usuários (CSM), a situação real da habitação (CMI) e uma proposta de melhoria inserindo um muro permeável (CMP). A figura 7 apresenta a velocidade média do fluxo de ar em cada ambiente de maior permanência e o critério de Cândido et al. (2010). Apresenta-se também a porcentagem de aproveitamento dos ventos nos ambientes internos.

A velocidade média do fluxo de ar interno indica que nos três casos analisados nenhum ambiente de maior permanência apresentou uma ventilação natural satisfatória para o alcance do conforto térmico (entre $0,4 \mathrm{~m} / \mathrm{s}$ e $0,8 \mathrm{~m} / \mathrm{s}$ ), destacando-se que o pior desempenho é quando temos a inserção do muro impermeável. As habitações de interesse social são entregues aos usuários sem os muros entre as edificações (CSM). Para esta configuração, nota-se que nenhum dos ambientes de maior permanência apresentou velocidades adequadas para o conforto térmico dos usuários. Nesse caso, a sala e o quarto dois tiveram velocidades internas perceptíveis, apresentando 17,2\% e $22,2 \%$, respectivamente, de aproveitamento dos ventos externos. Já no quarto 1 o fluxo de ar interno tem velocidades médias abaixo dos $0,2 \mathrm{~m} / \mathrm{s}$, ou seja, é imperceptível, registrando um aproveitamento dos ventos externos de apenas 9,3\%.

Segundo a NBR 15575 (ABNT, 2013) para a zona bioclimática 3, onde a cidade de Maringá - PR está inserida, as aberturas devem ter uma área efetiva para a ventilação maior ou igual a $7 \%$ da área do piso desse ambiente. De acordo com a tipologia das aberturas utilizadas na HIS analisada, em todos os ambientes de maior permanência as dimensões das aberturas estão de acordo com o estabelecido pela norma. O único ambiente que não atende a normativa é o banheiro, que não é classificado como ambiente de maior permanência, cujo valor está abaixo do recomendado (4,96\%),

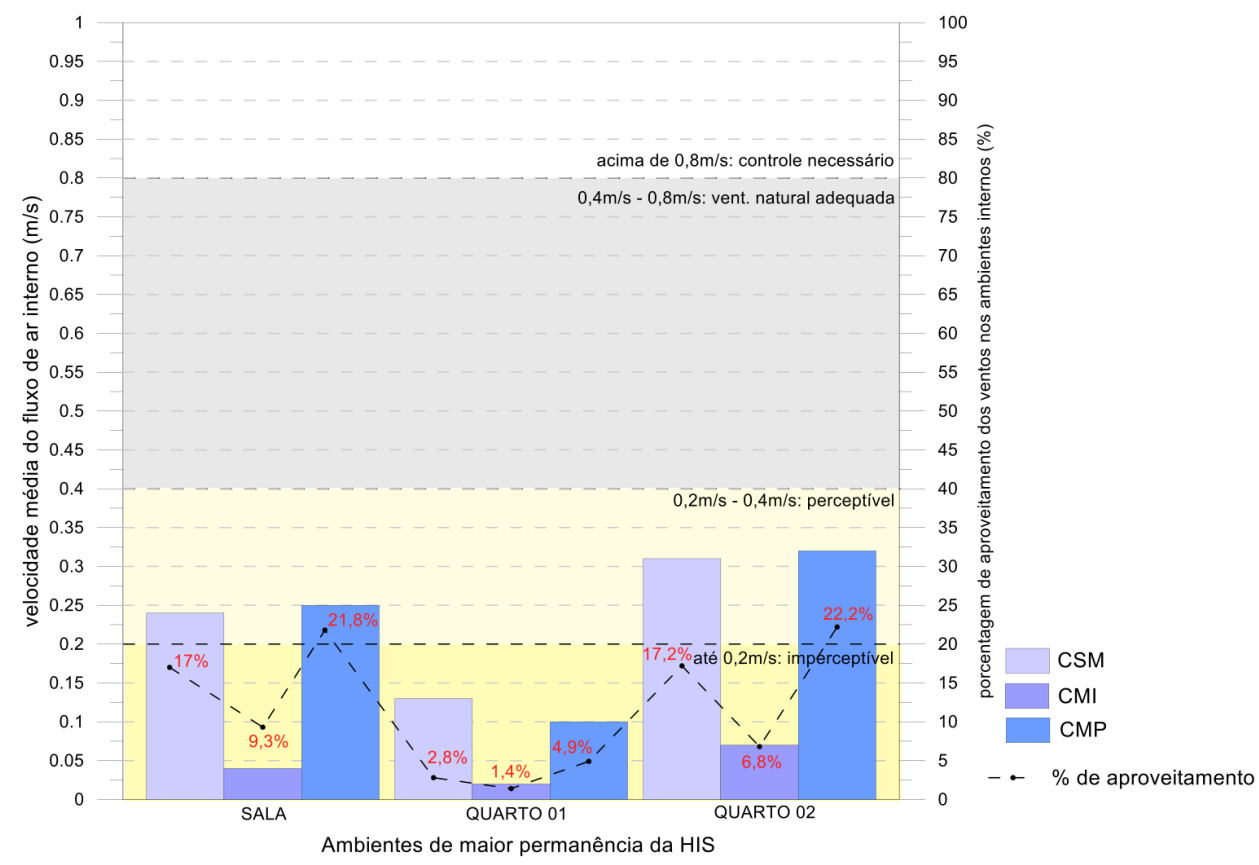




\begin{tabular}{|c|c|c|c|c|c|c|c|}
\hline Ambiente & Cód. & $\begin{array}{l}\text { Área } \\
\text { Abert. } \\
\left(\mathrm{m}^{2}\right)\end{array}$ & Tipo & $\begin{array}{c}\text { Percentual de } \\
\text { redução (\%) }\end{array}$ & $\begin{array}{l}\text { Área efetiva de } \\
\text { ventilação }\left(\mathrm{m}^{2}\right)\end{array}$ & $\begin{array}{l}\text { Área de } \\
\text { piso }\left(\mathrm{m}^{2}\right)\end{array}$ & $\begin{array}{c}\text { Área de ventilação } \\
\text { em relação à área } \\
\text { do piso (\%) }\end{array}$ \\
\hline \multirow{2}{*}{ Sala } & J01 & 2,40 & Correr e Fixa & 62,5 & 0,90 & \multirow{2}{*}{8,88} & 10,14 \\
\hline & P01 & 0,96 & Abrir & 0 & 0,96 & & - \\
\hline \multirow{2}{*}{ Quarto 1} & $\mathrm{~J} 02$ & 1,80 & Correr e Fixa & 62,5 & 0,68 & \multirow{2}{*}{7,25} & 9,31 \\
\hline & $\mathrm{P} 02$ & 0,96 & Abrir & 0 & 0,96 & & - \\
\hline \multirow{2}{*}{ Quarto 2} & $\mathrm{~J} 02$ & 1,80 & Correr e Fixa & 62,5 & 0,68 & \multirow{2}{*}{7,79} & 8,66 \\
\hline & P02 & 0,96 & Abrir & 0 & 0,96 & & - \\
\hline Cozinha & J02 & 1,80 & Correr e Fixa & 62,5 & 0,68 & 8,67 & 7,79 \\
\hline \multirow{2}{*}{ Banheiro } & $\mathrm{J} 03$ & 0,60 & Basculante $\left(45^{\circ}\right)$ & 70 & 0,18 & \multirow{2}{*}{3,63} & 4,96 \\
\hline & P02 & 0,96 & Abrir & 0 & 0,96 & & - \\
\hline
\end{tabular}

Tabela 3: Análise das aberturas segundo a NBR 15575. Fonte: Elaborado pelas autoras(2019). conforme apresentado na tabela 3. No entanto, apesar das aberturas estarem de acordo com o estabelecido no referido documento, isso não implica em uma ventilação adequada para os aspectos de conforto térmico dos usuários, conforme verificado nas simulações computacionais (figura 7).

Para o caso CSM, nota-se claramente que o fluxo de ar incide diretamente na abertura do quarto 2, apresentando uma aceleração do ar na passagem da abertura. No entanto, essas maiores velocidades não se distribuem ao longo de todo o ambiente interno, uma vez que o fluxo de ar apresenta uma recirculação dupla com redução dos valores de velocidade do fluxo de ar nas laterais do espaço (em torno de $0,25 \mathrm{~m} / \mathrm{s}$, existindo pontos com velocidades abaixo de $0,10 \mathrm{~m} / \mathrm{s}$ ). Apenas na região central, no sentido da abertura, têm-se velocidades que propicie uma ventilação natural adequada para o conforto térmico dos usuários (em torno de $0,6 \mathrm{~m} / \mathrm{s}$ ) (figura 8). Dos ambientes de maior permanência é o que apresenta as maiores velocidades do fluxo de ar (média em torno de $0,32 \mathrm{~m} / \mathrm{s}$ ), registrando um aproveitamento de $22,2 \%$, em relação aos ventos externos disponíveis (figura 7).

No quarto 1, tem-se uma redução significativa da velocidade do fluxo de ar interno $(9,3 \%)$, devido a sua posição a sotavento da face de incidência dos ventos externos dominantes. Nota-se claramente a falta de entrada do fluxo de ar nesse cômodo, registrando a quase total ausência de ventilação natural (velocidade média em torno de $0,1 \mathrm{~m} / \mathrm{s}$ ). Já na sala, apesar de sua posição também na região a sotavento, este ambiente está integrado com a cozinha, o que possibilita o acesso do fluxo de ar para esse cômodo. No entanto, a velocidade média do fluxo de ar interno é menor que no quarto 2 (17\% de aproveitamento dos ventos externos).

Quando os usuários mudam para a HIS, uma das principais modificações é a inclusão de um muro impermeável nas laterais do lote, devido a questões como privacidade 


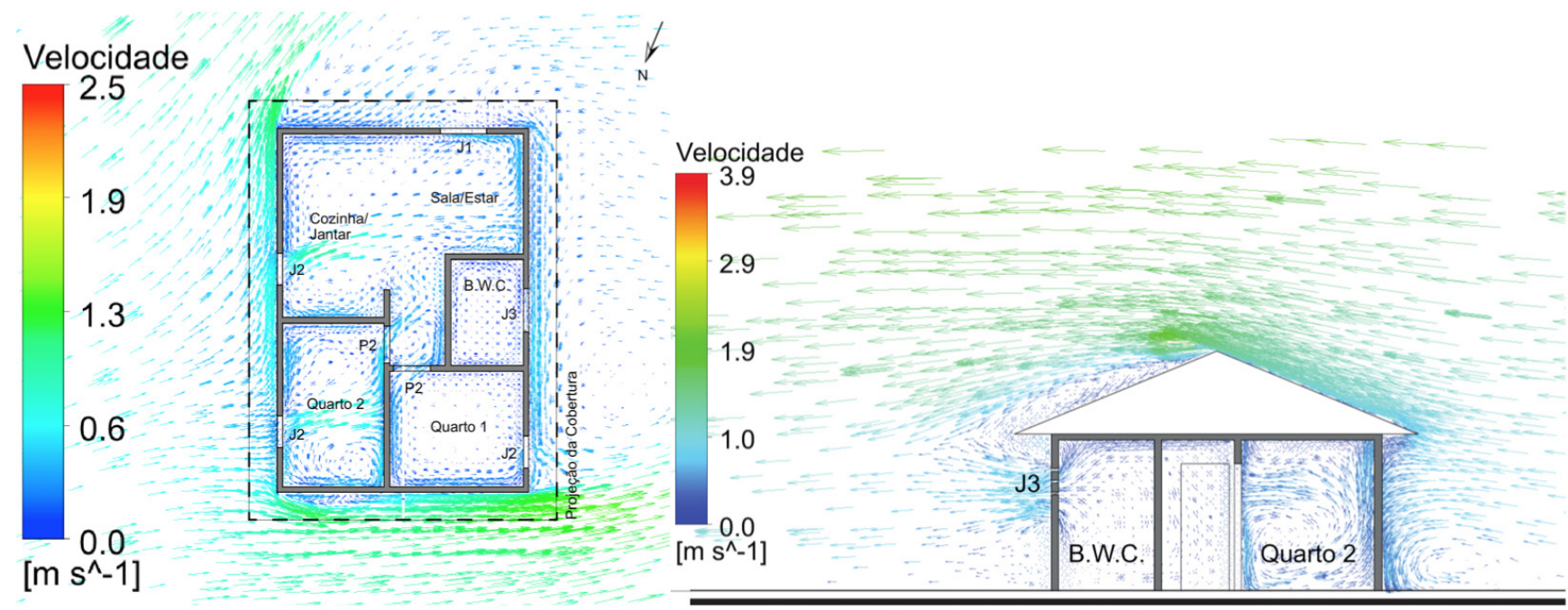

Figura 8: Vetores com velocidade e direção do fluxo de ar interno para ocaso CSM. Fonte: Elaborado pelas autoras (2019). e segurança dos moradores. No entanto, com relação ao conforto ambiental esses elementos se constituem como importantes obstáculos à livre circulação dos ventos com impacto significativo no conforto térmico dos usuários de edificações térreas em lotes pequenos, como as HIS.

Nesse caso (CMI), nota-se claramente que o muro é o elemento responsável pela redução da velocidade e da quantidade de ar que atinge os ambientes internos, reduzindo significativamente a ventilação natural dos ambientes internos da edificação. Novamente o quarto 2, devido a sua posição na face a barlavento, tem o melhor desempenho. No entanto, as velocidades internas são muito baixas (em torno de $0,06 \mathrm{~m} / \mathrm{s}$ ) aproveitando apenas $4,9 \%$ dos ventos externos. Em seguida, tem-se a sala com velocidades internas de $0,04 \mathrm{~m} / \mathrm{s}$ e o quarto 1 com praticamente ausência de ventilação natural $(0,02 \mathrm{~m} / \mathrm{s})$, registrando aproveitamento de $2,8 \%$ e 1,4\%, respectivamente (figura 7).

Qualitativamente nota-se claramente que a ventilação natural não ocorre de maneira satisfatória nos ambientes internos. Devido ao muro estar muito próximo, nota-se que há uma entrada reduzida do fluxo de ar nos ambientes internos, atingindo valores muito baixos e com estagnação do fluxo de ar interno. Na sala percebe-se o movimento do ar um pouco melhor do que nos outros ambientes, principalmente pela presença do beiral (em uma altura acima do muro) que, assim como as extremidades do muro de divisa, provoca um aumento da velocidade do ar que entra pela janela. Além disso, esse elemento faz com que parte do fluxo que seria desviado para cima da edificação seja direcionado para o interior da habitação. No entanto, esse fluxo de ar com velocidades maiores, não consegue penetrar nos ambientes de forma satisfatória. Além disso, fica evidente pelo corte que as extremidades do muro de divisa provocam um aumento da velocidade da corrente de ar, ocasionando uma grande sombra de vento sobre a cobertura da habitação, atingindo, em seguida, a região posterior do terreno com a formação de vórtices e velocidades significativamente reduzidas. Nota-se também que na lateral oposta 
Figura 9: Vetores com velocidade e direção do fluxo de ar interno para o caso CMI. Fonte: Elaborado pelas autoras (2019). aos ventos dominantes, forma-se uma área de recirculação com baixa velocidade do fluxo de ar (figura 9). Isso também foi constado na pesquisa de Da Costa et al. (2018).

Com relação à cozinha e ao quarto 1, é possível notar no corte que a presença do muro e a proximidade dele faz com que a habitação fique na área de sombra de vento, o que potencializa a reduzida ventilação desses ambientes. Dessa forma, vê-se que a pequena quantidade de ar que entra na edificação apresenta baixa velocidade e não atinge uma região significativa do ambiente interno. Ressalta-se ainda que, o quarto 1 consegue ter uma distribuição melhor do ar devido a porta do ambiente estar aberta.

Da Costa (2018) ressalta que a utilização de muros vazados se configura como um interessante recurso para reduzir o efeito negativo proporcionado por esses componentes, podendo apresentar potencialidades favoráveis a um melhor aproveitamento da ventilação natural, sem afetar a sensação de privacidade e a segurança dos usuários. Dessa forma, o terceiro caso analisado foi à inserção de um muro permeável na HIS (CMP). Nota-se claramente uma melhora significativa em relação ao caso com muro impermeável (CMI) e uma proximidade com o caso sem muro (CSM). Novamente o melhor desempenho foi no quarto $2(21,8 \%)$ seguido da sala (17\%) e do quarto $1(6,8 \%)$ com o pior desempenho (figura 7), pelos mesmos motivos relatados anteriormente. Assim, constata-se que é melhor a inserção do muro vazado, pois tem-se um desempenho similar ao caso sem muro, mantendo a segurança e a privacidade dos moradores (figura 10).

Com essas análises quantitativas nota-se claramente que a inserção do muro (CMI) não permite que os ventos externos alcancem a edificação, prejudicando

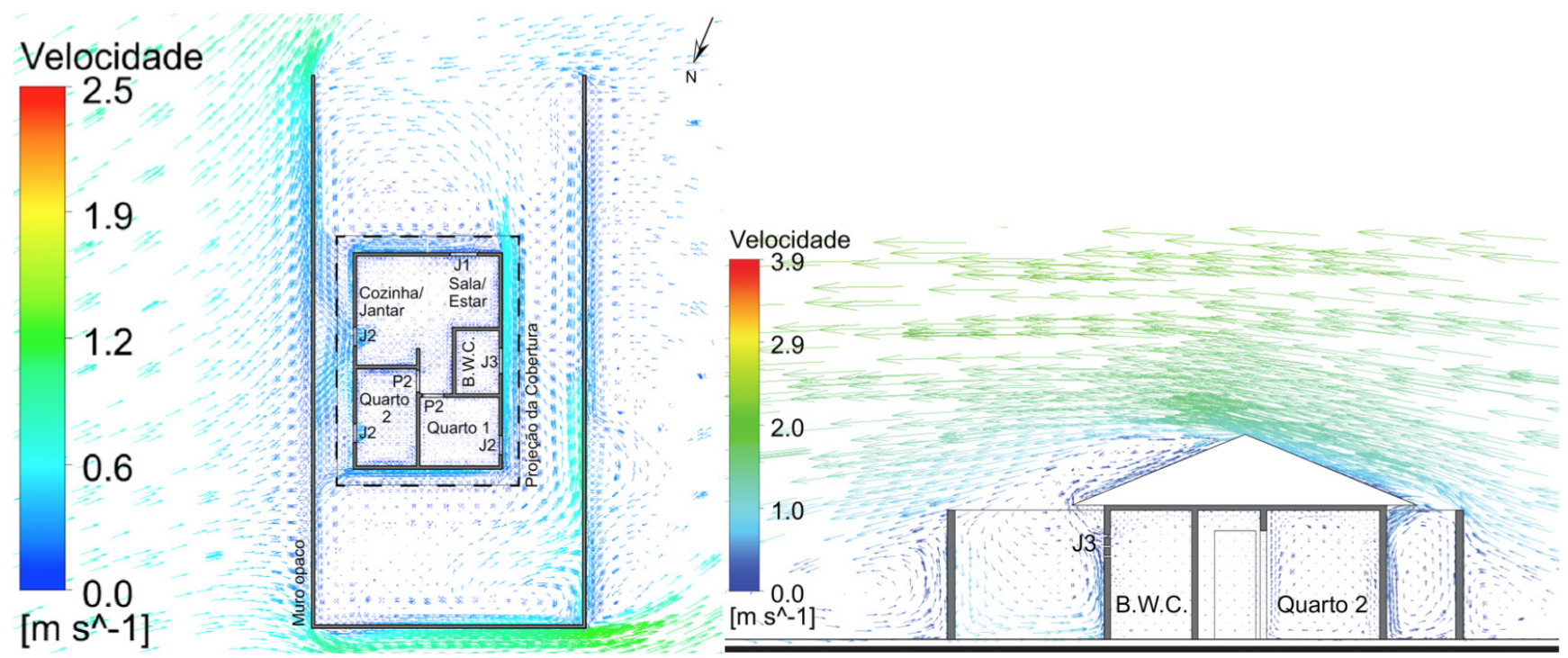




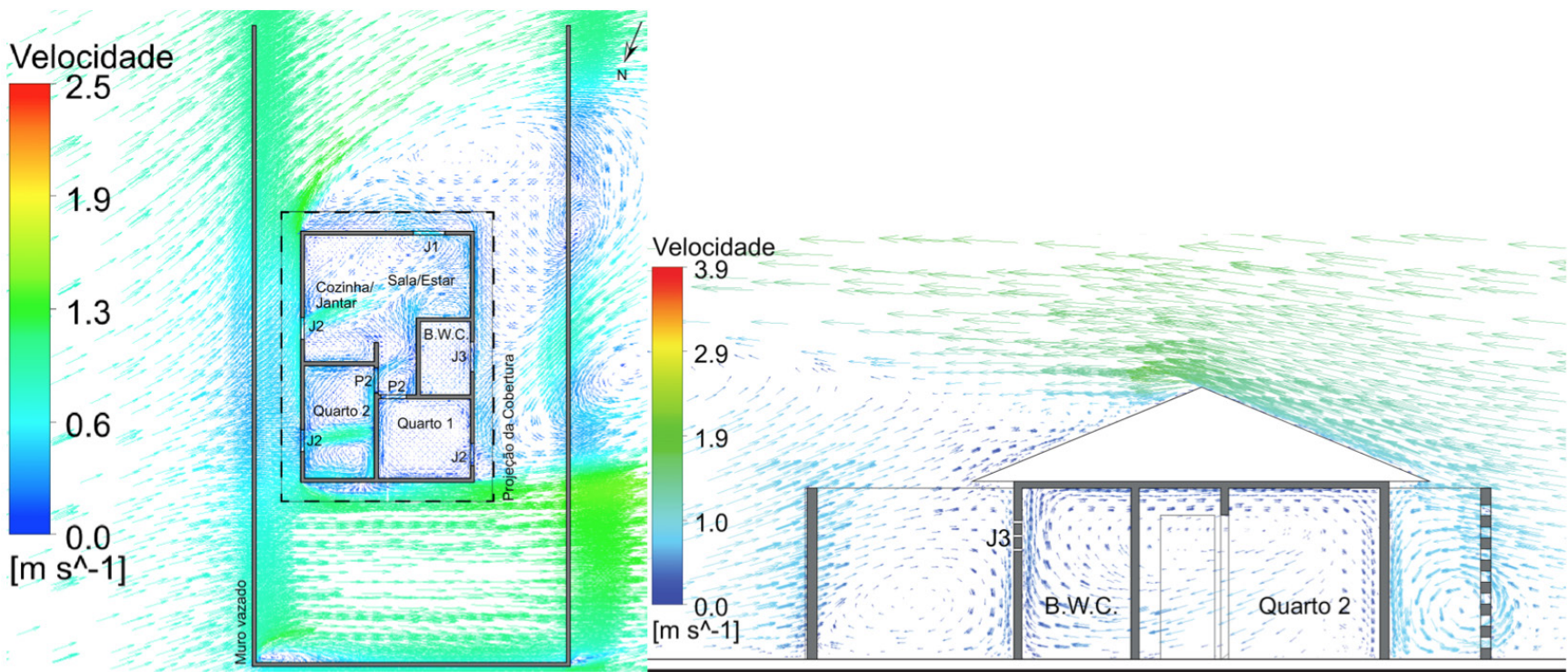

Figura 10: Vetores com velocidade e direção do fluxo de ar interno para o caso CM. Fonte: Elaborado pelas autoras (2019). significativamente o conforto térmico dos usuários. Na região a barlavento do muro, em todos os casos analisados, na altura das aberturas da HIS, o vento externo tem velocidade de $0,75 \mathrm{~m} / \mathrm{s}$. A medida que vai se aproximando do muro, ainda na região a barlavento, Já é possível notar uma redução das velocidades em função da influência do muro e da edificação na camada limite atmosférica, sendo a redução mais intensa no CMI seguido do CMP. Logo após o muro (região a sotavento e externo a edificação), no CMI esses valores sofrem uma redução de $83 \%$, atingindo valores de $0,13 \mathrm{~m} / \mathrm{s}$. Com o muro permeável essa redução, em relação ao ponto 1 sem nenhuma obstrução, é menos intensa (49\%). Isso ocorre devido ao efeito venturi, onde um fluído em escoamento constante atravessa uma região mais estreita, reduzindo a sua pressão e, assim, aumentando a sua velocidade após atravessar essa seção, como o caso do muro permeável (CMP). Ressalta-se que nesse caso, a velocidade do fluxo de ar nessa região é, inclusive, levemente superior que o caso sem muro (CSM). Com essas porcentagens fica claro que a inserção do muro (CMI) não permite que os ventos externos alcancem a edificação, prejudicando o conforto térmico dos usuários e que o muro permeável (CMP) possibilita o alcance da corrente de ar com maiores velocidades na edificação (figura 11).

Por fim, a ação dos ventos sobre um edifício exerce diferentes forças nas aberturas provocando o movimento do ar no espaço interno. Essa ação traduz-se em pressões distribuídas sobre as envoltórias do edifício que indicam o potencial de uma abertura para insuflar (pressão positiva) ou extrair (pressão negativa) o ar em determinado ambiente. Conhecer a distribuição dessas pressões nas superfícies do edifício é importante para avaliar as cargas de vento e as estimativas do fluxo de ar por ação dos ventos. $O$ desempenho dos casos avaliados anteriormente é comprovado através da figura 12 apresenta os valores médios dos Cps nas aberturas da HIS, para cada caso avaliado. 
Figura 11: Velocidade dos ventos ao longo do percurso até atingir a edificação. Fonte: Elaborado pelas autoras (2019).

Figura 12: Valores médios de $\mathrm{Cp}$ nas aberturas para todos os casos analisados. Fonte: Elaborado pelas autoras (2019)
Nos casos com muro permeável e sem muro, as aberturas dos ambientes localizados na fachada de incidência dos ventos dominantes (região à barlavento) apresentam valores de $\mathrm{Cp}$ positivos (A1 e A3), indicando a entrada de ar. No caso da sala, a abertura localizada na face lateral, devido a sombra de vento que contorna a edificação, apresenta $C p$ cujo valor é negativo (indicando a saída de ar), $\operatorname{com} \Delta C p=0,42$ e $\Delta C p=0,49$ para o CSM e CMP, respectivamente, o que comprova o desempenho levemente superior do fluxo de ar interno com o muro permeável, descrito anteriormente. No caso do quarto 2 a porta interna mantida aberta (A4) funciona como saída de ar (Cp -), o que possibilita a movimentação do ar nesse ambiente. Isso é comprovado pela diferença de pressão entre as aberturas de entrada e saída de ar, cujos valores foram de $\Delta \mathrm{Cp}=$ 0,32 e $\Delta C p=0,30$ para o CSM e CMP, respectivamente (Figura 12).
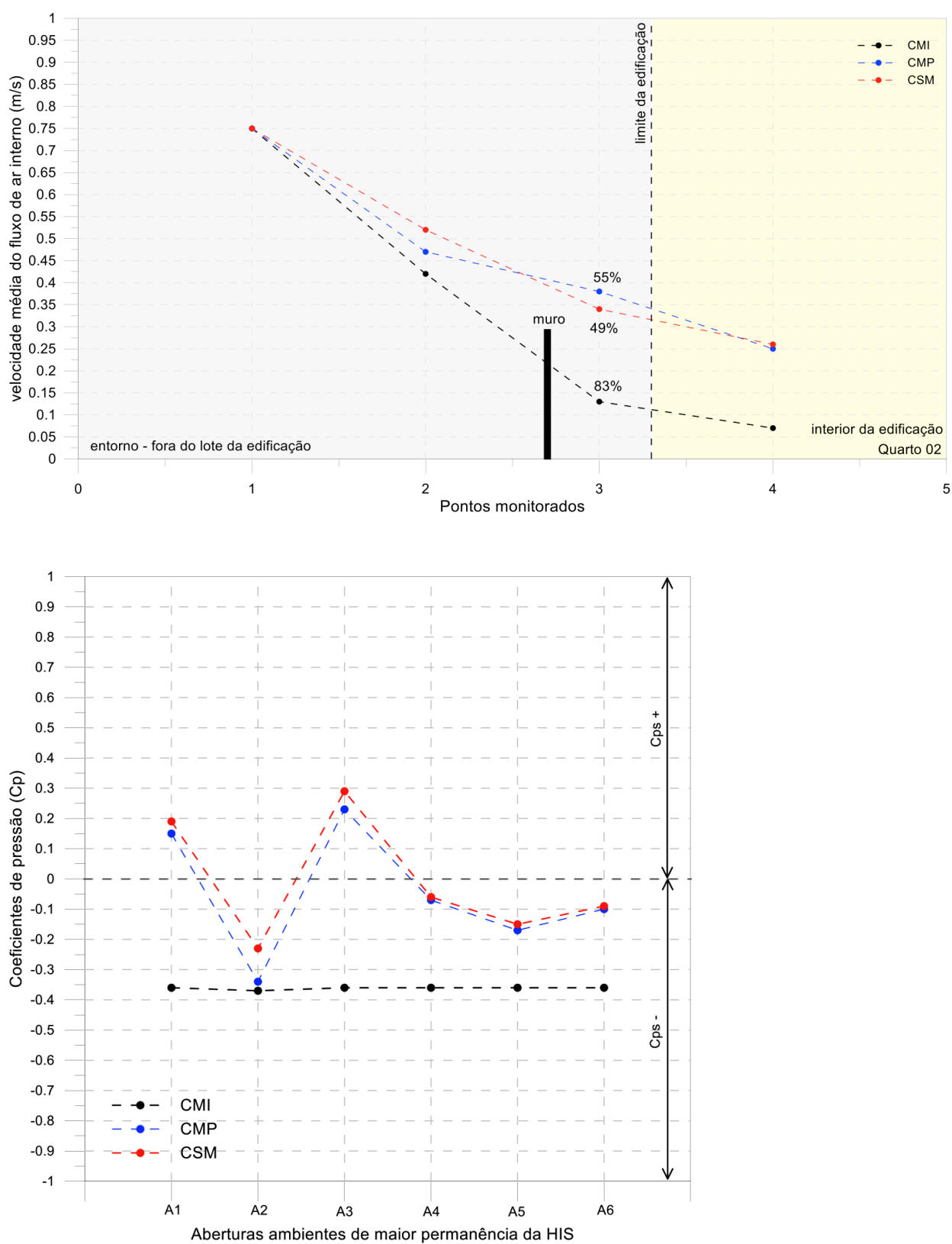
No quarto 1, os valores de $\mathrm{Cp}$ de ambas as aberturas (porta interna - A6 e abertura na fachada - A5) são negativos, pois a abertura externa se localiza na região sotavento, não apresentando nenhum ponto de pressão positiva e entrada de ar no ambiente, o que também comprova o seu desempenho reduzido. As diferenças das pressões entre as aberturas desse ambiente são de $\Delta C p=0,06$ e $\Delta C p=0,07$ para o CSM e CMP, respectivamente. Por fim, no $\mathrm{CMl}$, todas as aberturas apresentam valores de $\mathrm{Cp}$ negativos e muito similares, o que ocasiona $\Delta C p=0$, dificultando o fluxo de ar interno. As aberturas localizadas na face a barlavento (A1 e A3), devido a barreira ocasionada pelo muro, ficam em uma região com sombra de vento, o que ocasiona os valores negativos de $\mathrm{Cp}$.

\section{Conclusões}

Os projetos das Habitações de Interesse Social seguem um padrão que na maioria das vezes desconsidera as características climáticas da região. Dessa forma, tem-se edificações com baixa qualidade, principalmente com relação ao conforto ambiental. Com relação as aberturas dos ambientes de maior permanência da habitação analisada, notou-se que apesar destas estarem de acordo com o estabelecido na NBR 15575 (2013), isso não implica em uma ventilação adequada para os aspectos de conforto térmico dos usuários. Diante disso, a edificação sem muro lateral já apresenta um desempenho da ventilação natural abaixo do adequado para o alcance do conforto térmico. Com a inclusão do muro impermeável no perímetro do lote, nota-se claramente a redução da velocidade e da quantidade de ar que atinge os ambientes internos, reduzindo significativamente a ventilação natural dos ambientes internos da edificação. Por fim, com o uso de muros permeáveis tem-se uma melhora significativa em relação ao caso com muro impermeável e uma proximidade com o caso sem muro. Dessa forma, o uso do muro permeável se configura como um interessante recurso para reduzir o efeito negativo proporcionado por esses componentes, podendo apresentar potencialidades favoráveis a um melhor aproveitamento da ventilação natural, sem afetar a sensação de privacidade e a segurança dos usuários. No entanto, ressalta-se que é uma estratégia que apresenta pontos negativos, como a manutenção em relação a limpeza. Por fim, conclui-se que os parâmetros exigidos pelas normativas não são condizentes com o nível de conforto dos usuários, atendendo, apenas, os requisitos de salubridade. Dessa forma, enfatiza-se a necessidade de revisão dos parâmetros mínimos das normas, considerando o conforto térmico dos usuários.

\section{Referências bibliográficas}

AMERICAN SOCIETY OF HEATING, REFRIGERATING AND AIR CONDITIONING ENGINEERS. ASHRAE 55: Thermal Environmental Conditions for Human Occupancy. American Society of Heating, Refrigerating and Air-Conditioning Engineers. Atlanta, 2004.

ANDRADE, N. C. Estudo da Ventilação Natural em Edificações Com Captadores de Vento Multidirecionais Por Meio de Ensaios em Túnel de Vento e Simulações Computacionais. 2013. Tese (Doutorado em Arquitetura, Tecnologia e Cidade) - Faculdade de Engenharia Civil, Arquitetura e Urbanismo, Universidade Estadual de Campinas, Campinas, 2013.

ASSOCIAÇÃO BRASILEIRA DE NORMAS TÉCNICAS. NBR 15220: Desempenho térmico de edificações - Parte 3: Zoneamento bioclimático brasileiro e diretrizes construtivas para habitações unifamiliares de interesse social. Rio de Janeiro, 2005.

NBR 15575: Edificações habitacionais: Desempenho - Parte 1: Requisitos gerais. Rio de Janeiro, 2013 
BITTENCOURT, L. S.; CÂNDIDO, C. Introdução a ventilação natural. Maceió: EDUFAL, 2006.

BRANDÃO, R. S. As interações Espaciais Urbanas e o Clima. 2009. Tese (Doutorado em Arquitetura e Urbanismo) - Faculdade de Arquitetura e Urbanismo, Universidade de São Paulo, São Paulo, 2009.

CALAUTIT, J. K.; HUGHES, B. R. Wind tunnel and CFD study of the natural ventilation performance of a commercial multi-directional wind tower. Journal of Wind Engineering \& Industrial Aerodynamics, v. 80, p. 71-83, out. 2014. DOI: https://doi.org/10.1016/j. buildenv.2014.05.022.

CÂNDIDO, C.; DEAR, R. J. de; LAMBERTS, R.; BITTENCOURT, L. Air movement acceptability limits and thermal comfort in Brazil's hot humid climate zone. Building and environment, v. 45, n. 1, p. 222-229, jan. 2010. DOI: https://doi.org/10.1016/j.buildenv.2009.06.005.

CARVALHO, M. T. M.; SPOSTO, R. M. Metodologia para avaliação da sustentabilidade de habitações de interesse social com foco no projeto. Ambiente Construído, v. 12, n. 1, p. 207-225, jan./mar. 2012. DOI: http://dx.doi.org/10.1590/S1678-86212012000100014.

CHEN, Q. Ventilation Performance Prediction for Buildings: a method overview and recent applications. Building and Environment, v. 44, n. 4, p. 848-858, abr. 2009. DOI: https:// doi.org/10.1016/j.buildenv.2008.05.025

COSTA, F. J. de M. Ventilação e Prescrições Urbanísticas: uma aplicação simulada no bairro de Petrópolis em Natal/RN. 2001. Dissertação (Mestrado em Arquitetura e Urbanismo)Programa de Pós-Graduação em Arquitetura e Urbanismo, Universidade Federal do Rio Grande do Norte, Natal, 2001.

DA COSTA, I. P. C.; BARBOSA, R. V. R.; BARBIRATO, G. M. Desempenho da ventilação natural em diferentes configurações de muros vazados laminados. In: XVII ENCONTRO NACIONAL DE TECNOLOGIA DO AMBIENTE CONSTRUíDO, 2018, Foz do Iguaçu. Anais [...]. Foz do Iguaçu: ANTAC, 2018.

COSTA, L. Aproveitamento da ventilação natural nas habitações: um estudo de caso na cidade de Aracaju - SE. Dissertação (Mestrado em Tecnologia da Arquitetura) - Faculdade de Arquitetura e Urbanismo, Universidade de São Paulo, São Paulo, 2009.

CÓSTOLA, D. Ventilação Por Ação do Vento no Edifício: procedimentos para quantificação. São Paulo, 2006. Dissertação (Mestrado em Arquitetura e Urbanismo, Tecnologia da Arquitetura) - Faculdade de Arquitetura e Urbanismo, Universidade de São Paulo, São Paulo, 2006.

CÓSTOLA, D.; ALUCCI, M. Pressure coefficient simulated by CFD for wind-driven ventilation analysis. In: BUILDING SIMULATION, 2007, Beijing. Proceedings [...]. Beijing, 2007. P. 999-1006.

EN15251, CEN Standard et al. Indoor environmental input parameters for design and assessment of energy performance of buildings addressing indoor air quality, thermal environment, lighting and acoustics. Thermal Environment, Lighting and Acoustics, European Committee for Standardization, Brussels, 2007.

FERREIRA, C. C.; SOUZA, H. A. de; ASSIS, E. S. de. Discussão dos limites das propriedades térmicas dos fechamentos opacos segundo as normas de desempenho térmico brasileiras. Ambiente Construído, v. 17, n. 1, p. 183-200, 2017. DOI: http://dx.doi.org/10.1590/ s1678-86212017000100131.

FRANKE, J.; HIRSCH, C.; JENSEN, A. G.; KRÜS, H. W.; SCHATZMANN, M.; WESTBURY, P. S.; WISSE, J. A.; WRIGHT, N. G. Recommendations on the use of CFD in predicting pedestrian wind environment. In: Cost action C (Vol. 14). Bruxelas, 2004.

GIVONI, B. Basic Study of Ventilation Problems in Houses in Hot Countries. Israel: Building Research Station of the Institute of Technology, 1962.

GRIGOLETTI, G. de C.; LINCK, G. I. Análise de comportamento térmico de HIS térreas unifamiliares em Santa Maria, RS. Ambiente Construído, v. 14, n. 2, p. 109-123, abr./jun. 2014. DOI: <https://doi.org/10.1590/S1678-86212014000200008>. 
HARRIES, A. Notas de aula. In: Workshop: CFX - FAU/USP. São Paulo, 2005.

INSTITUTO NACIONAL DE METEOROLOGIA (INMET). Disponível em: <http://www.inmet.gov. br/portal/>. Acesso em: dez. 2018.

INTERNATIONAL ORGANIZATION FOR STANDARDIZATION. ISO 7730: Ergonomics of the thermal environment - Analytical determination and interpretation of thermal comfort using calculation of the PMV and PPD indices and local thermal comfort criteria. 2005.

KOPPEN, W. Climatologia: com um estúdio de los climas de la tierra. México: Fondo de Cultura Economia, 1948. 478p.

LAMBERTS, R.; DUTRA, L.; PEREIRA, F. O. R. Eficiência energética na arquitetura. São Paulo: PW, 2014.

LEITE, C. G. Alterações da Ventilação Urbana Frente ao Processo de Verticalização de Avenidas Litorânea. 2008. Dissertação (Mestrado em Arquitetura e Urbanismo) - Faculdade de Arquitetura e Urbanismo, Universidade de São Paulo, São Paulo, 2008.

LEITE, R. V. Fortaleza, Terra do Vento: a influência da mudança nos padrões de ocupação do solo sobre a ventilação natural em cidade de clima tropical úmido. São Paulo, 2010. Dissertação (Mestrado em Arquitetura e Urbanismo, Tecnologia da Arquitetura) - Faculdade de Arquitetura e Urbanismo, Universidade de São Paulo, São Paulo, 2010.

LÔBO, D. G. F.; BITTENCOURT, L. S. A influência dos captadores de vento na ventilação natural de habitações populares localizadas em climas quente e úmidos. Ambiente Construído, v. 3, n. 2, p. 57-67, abr./jun. 2003.

LUKIANTCHUKI, M. A. Sheds Extratores e Captadores de Ar Para Indução da Ventilação Natural em Edificações. São Carlos, 2015. Tese (Doutorado em Arquitetura e Urbanismo)- Instituto de Arquitetura e Urbanismo, Universidade de São Paulo, São Carlos, 2015.

LUKIANTCHUKI, M. A., SHIMOMURA, A. R. P., DA SILVA, F. M., \& CARAM, R. M. Sheds Extratores e Captadores de Ar: influência da geometria e da dimensão das aberturas no desempenho da ventilação natural nas edificações. Ambiente Construído, v. 16, n. 1, p. 83-104, 2016. DOI: <https://doi.org/10.1590/s1678-86212016000100062>.

MARQUES DA SILVA, F. Aplicação da ventilação natural e mista em edifícios: as ações introdutoras da ventilação natural. In: Cadernos Edifícios, n.6, p. 7-26, 2010.

MERCADO, M. V.; ESTEVES, A.; FILLIPÍN, C. ComportamientoTermico-Energético de Una Vivienda Social de la Ciudad de Mendonza, Argentina. Ambiente Construído, v. 10, n. 2, p. 87-100, abr./jun. 2010. DOI: https://doi.org/10.1590/S1678-86212010000200006.

MORAIS, J. S. C.; GALVÃO, C. O.; LABAKI, L. C. Velho edifício, novas aberturas: simulação de ventilação natural por meio de CFD. In: XVII ENCONTRO NACIONAL DE TECNOLOGIA DO AMBIENTE CONSTRUÍDO, 2017, Balneário Camboriú. Anais [...]. Balneário Camboriú: ANTAC, 2017.

MORAIS, Juliana M. da S. C.; LABAKI Lucila C. CFD como ferramenta para simular ventilação natural interna por ação dos ventos: estudos de caso em tipologias verticais do "Programa Minha Casa, Minha Vida". Ambiente Construído, v. 17, n. 1, p. 223-244, jan./mar. 2017. DOI: http://dx.doi.org/10.1590/s1678-86212017000100133.

NASCIMENTO, D. M.; BRAGA, R. C. Q. Déficit habitacional: um problema a ser resolvido ou uma lição a ser aprendida? Risco: Revista de pesquisa em Arquitetura e Urbanismo, p. 98109, 2009. DOI: https://doi.org/10.11606/issn.1984-4506.v0i9p98-109.

PRATA-SHIMOMURA, A. R. Impacto da Altura de Edifícios nas Condições de Ventilação Natural do Meio Urbano. São Paulo, 2005. Tese (Doutorado em Arquitetura e Urbanismo, Tecnologia da Arquitetura) - Faculdade de Arquitetura e Urbanismo, Universidade de São Paulo, São Paulo, 2005.

PROJETANDO EDIFICAÇÕES ENERGETICAMENTE EFICIENTES - PROJETEEE. Disponível em: $<$ http://projeteee.mma.gov.br/>. Acesso em: dez. 2018. 
RABELO, P.; TAFRA, S.; PALMA, J. Analysis of Environmental Performance in a Social Housing: housing complex at Conchalí, Santiago of Chile. In: PASSIVE AND LOW ENERGY ARCHITECTURE, 28, Lima, 2012. Proceedings [...]. Lima: PLEA, 2012.

RAMPONI, R.; BLOCKEN, B. CFD simulation of cross-ventilation for a generic isolated building: impact of computational parameters. Building and Environment, v. 53, p. 34-48, 2012. DOI: <https://doi.org/10.1016/j.buildenv.2012.01.004>.

REIS, A. T. da L.; LAY, M. C. D. O projeto da habitação de interesse social e a sustentabilidade social. Ambiente Construído, v. 10, n. 3, p. 99-119, jul./set. 2010. DOl: https://doi. org/10.1590/S1678-86212010000300007.

TOMINAGA, Y.; MOCHIDA, A.; YOSHIE, R.; KATAOKA, H.; NOZU, T.; YOSHIKAWA, M., \& SHIRASAWA, T. AIJ guidelines for practical applications of CFD to pedestrian wind environment around buildings. Journal of wind engineering and industrial aerodynamics, v. 96, n. 10-11, p. 1749-1761, 2008. DOI: <https://doi.org/10.1016/j.jweia.2008.02.058>. 